\title{
Challenges in Acculturation among International Students from Asian Collectivist Cultures
}

\author{
Kyunghee $\mathrm{Ma}^{1}$, Ronald Pitner ${ }^{1}$, Izumi Sakamoto ${ }^{2} \&$ Hyun Young Park ${ }^{3}$ \\ ${ }^{1}$ College of Social Work, University of South Carolina, South Carolina, USA \\ ${ }^{2}$ Factor-Inwentash Faculty of Social Work, University of Toronto, Toronto, Canada \\ ${ }^{3}$ Toronto, Canada \\ Correspondence: Kyunghee Ma, 1512 Pendleton St., Hamilton College, Columbia, SC, 29208, USA. Tel: \\ 1-803-777-6767. E-mail: kyunghee@email.sc.edu
}

$\begin{array}{lc}\text { Received: May 9, 2020 } & \text { Accepted: May 28, 2020 Online Published: June 16, } 2020 \\ \text { doi:10.5539/hes.v10n3p34 } & \text { URL: https://doi.org/10.5539/hes.v10n3p34 }\end{array}$

\begin{abstract}
Many international students coming to a U.S. university, especially those coming from a collectivist culture such as Asia, experience acculturation stress due to encountering different cultural norms and values. Lack of available resources may limit their coping ability, and prolonged exposure to acculturation stress may result in a decline in mental health. Asian international students may be at greater risk of developing mental health complications due to additional stressors derived from their cultures such as family recognition through success, emphasis on emotional self-control, and stigma toward mental illness. In this context, accumulated and unresolved acculturation stress may increase psychological vulnerabilities. Despite its relevance, there is no conceptual framework examining acculturation experiences of this student population. This article aims to present a conceptual framework of the acculturation process of Asian international students. Such a framework is important because it not only provides a holistic understanding of the acculturation process for Asian international students, but also provides an avenue for a comprehensive empirical inquiry. Furthermore, research-based evidence will help inform a more effective and inclusive university policy addressing the various needs of international students in order to provide intervention when necessary.
\end{abstract}

Keywords: acculturation stress, Asian international students, collectivist, mental health, social support

\section{Introduction}

Over the past sixty years, systematic efforts have been made to increase international exposure on campus in the United States (US). According to Open Doors 2019 published by the Institute of International Education, during the 1948-1949 academic year, 25,464 international students enrolled in institutes of higher education, accounting for $1 \%$ of the total enrollment in U.S. universities. Since then, the number of international students has continued to grow. During 2018-2019, the enrollment reached a record high with 1,095,299 international students enrolled in various degree programs, bringing an estimated 44.7 billion dollars to the U.S. economy. The three most represented countries for international student enrollment are China, India, and South Korea, providing more than half of the entire international student population. Given this increase, more research is needed to examine how these students adjust to their new culture.

Berry (1992) identifies acculturation stress as difficulties that arise in the process of cultural adjustment. Adjusting to a new culture is demanding and exhausts psychological resources, which often creates acculturation stress (Smart \& Smart, 1995). Studies have shown that, during the cross-cultural transition, many international students experience acculturation stress due to conflicting cultural norms, values, and expectations (Smith \& Khawaja, 2011). Prolonged exposure to acculturation stress may lead to mental health challenges (Berry, 2005; Berry, Kim, Minde, \& Mok, 1987; Zhang \& Goodson, 2011).

Resorting to a generalization process to describe different cultural variations is a risk when studying individuals' social behaviors and interactions. Caution is required for researchers not to use a reductionist approach (Voronov \& Singer, 2002). It is important to acknowledge the complexity of human behaviors within a particular culture. However, as a broad generalization for the purpose of this manuscript, several Asian cultures tend to see individuals as embedded in groups and emphasize the pursuit of common interest (Hui \& Triandis, 1986). This 
can be viewed as collectivist. A more complex definition will be elaborated on below. Many Asian international students, who typically value their family and friends as vital sources of support in stressful situations, may be particularly vulnerable to depression (Zhang, 2012), because they often work under tremendous internal pressure to excel at school in order to honor their family (Yan \& Berliner, 2011). Asian cultures place greater emphasis on emotional self-control (Kim, $\mathrm{Li}, \& \mathrm{Ng}, 2005)$ and greater stigmatization of psychological distress than Western cultures (Hays \& Erford, 2014). As a consequence, some students from Asian cultures may be less willing than American students to seek outside help for psychological distress (Li \& Lin, 2014). In this context of adjustment, isolation from their primary support group may adversely affect students who have not established social support patterns similar to those in their home countries. Despite the scope, growth, and importance of this problem, there is little theoretical understanding of the impact of acculturation stress on the mental well-being of international students from Asian cultures.

It is not the purpose of this analysis to discuss details that make a culture distinct. Instead, the scope is confined to the overall tendencies of Asian international students and how they adjust to American culture. This manuscript aims to provide a conceptualization of the relationship between acculturation stress and mental health concerns among Asian international students during their university studies in the US. More specifically, using the framework of an acculturation process, we present a comprehensive conceptual model that examines underpinning theoretical assumptions and key concepts concerning acculturation stress and mental health. While existing literature addresses common acculturation issues of immigrants and refugees, there is a paucity of conceptualization about the effects of acculturation stress on the mental health of Asian international students. Given that this group represents the largest percentage of international students in the US, more inquiry is needed in this area. This manuscript will fill this gap in the literature by providing a conceptual model that will help guide further research inquiry into the association between acculturation stress and mental health concerns.

\section{Terms and Definitions}

It is important to begin this discussion by defining key terms. In this manuscript, international students refers to "students who have crossed a national or territorial border for the purposes of education and are now enrolled outside their country of origin" (UNESCO Institute for Statistics, 2006, p. 178). This definition excludes refugees and immigrants who generally move to the host country for permanent settlement purposes. International students typically come to the host country with specific academic goals in mind, and the majority of them plan to return to their homeland upon completing their studies. Therefore, full cultural adaptation may not occur in this population.

Collectivist culture emphasizes interdependence, harmony, conformity, and reciprocity. More often, in collectivist cultures, people have a strong emotional attachment to their in-groups and tend to subjugate their individual interests for the good of the group. Their goals are communal, and achievements are viewed as a result of collective effort. Members of collectivist cultures desire to contribute to family integrity by fulfilling their social and familial roles. Collectivism is commonly observed in Asian, African, and Latin American cultures (Triandis, 1995).

Collectivist culture stands in stark contrast to individualist culture, which fosters independence, autonomy, assertiveness, and personal achievement. This individualism creates weaker bonds within in-groups. That is, broader and more inclusive yet superficial in-groups are considered the norm. In this culture, personal distinctiveness is greatly emphasized. Individual needs typically outweigh group interests, and achievements are perceived as a result of individual ability. Individualism is mostly seen in cultures of North America and Western Europe (Triandis, 1995).

It is important to note that in most cultures, collectivist and individualist cultures, co-exist with different proportions and emerge in different contexts (Coon \& Kemmelmeier, 2001). What was described above represents general patterns of collectivism and individualism, which are dominant characteristics shared as a whole, but will not necessarily be displayed by everyone in these cultures. In spite of these shortcomings, this conceptual model has significant value in explaining acculturation experiences of international students from collectivist cultures, namely Asian cultures.

\section{Literature Review}

\subsection{Theoretical Underpinnings}

Acculturation refers to "the dual process of cultural and psychological change that takes place as a result of contact between two or more cultural groups and their individual members" (Berry, 2005, p. 698). It is a reciprocal, multidimensional process that affects individuals through re-socialization (Zea, Asner-Self, Birman, 
\& Buki, 2003). Initially, acculturation research was generally focused on immigrants, based on the premise that they would discard their cultural heritage and develop new identities in the host culture. However, acculturation theory has been modified over the past three decades to a bi-directional process model, drawing attention to the fact that migrants adopt practices, values, and identifications with the host culture, but still retain those from their culture of origin (Schwartz, Unger, Zamboanga, \& Szapocznik, 2010).

Acculturation occurs both at group and individual levels (Berry, 1997, 2005). Group-level acculturation involves changes in social and institutional structures as well as cultural practices; conversely, individual-level acculturation entails shifts within the individual's psychological and behavioral state. The psychological components reflect the internal aspect of adaptation, which includes beliefs, values, attitudes, and expectations; the behavioral dimension pertains to the external aspects in relation to how individuals adopt the host culture through social interactions.

During intercultural contact, it is not unusual for individuals to encounter conflicts that may lead to behavioral and psychological shifts while accommodating a new culture. Acculturation stress evidences itself during cross-cultural transitions when individuals face adjustment difficulties that exceed their available coping resources (Berry, 2005). When this occurs, individuals appraise their acculturation experiences as problematic, struggling to cope with challenges. Without social support, acculturation stress persists, adversely affecting individuals' psychological well-being (Lee, Koeske, \& Sales, 2004; Yeh \& Inose, 2003; Zhang \& Goodson, 2011). Prolonged exposure to acculturation stress may lead to mental health complications (Smith \& Khawaja, 2011).

While examining how sojourners, including international students, have adjusted to the new culture through re-socialization, Gudykunst (2005) identified four needs that must be met to make a successful transition: a sense of predictability, a sense of group inclusion, an avoidance of extensive anxiety, and a sense of sustained self-concept. When these needs are unmet, sojourners will experience increased levels of uncertainty and anxiety, which diminishes their ability to successfully interact with host nationals. Failing to reduce uncertainty and anxiety will result in a decline in sojourners' emotional well-being. As temporary residents who have not established permanent social support in the host culture, international students are more vulnerable to the negative influence of acculturation challenges (Berry et al., 1987). Despite the clear need for a greater focus on acculturation stress, many university services for international students tend to tailor their programs toward academic progress and immigration regulations. This oversight highlights the lack of emotional and social support available to the students.

Coping plays an important role in the acculturation process in ameliorating the negative impact of acculturation stress. Subject to contextual influences, coping is a process of managing the demands of a person-environment relationship and the ensuing emotional responses originating from the situation (Lazarus \& Folkman, 1984). Employing problem-focused and active coping strategies is considered effective in promoting positive adaptation and emotional health (Kuo, 2014). From a stress and coping perspective, acculturation theory takes on an ecological perspective, which focuses on the interactions between the individual's personal system and his or her external environment during cross-cultural transitions (Kuo, 2014). In this framework, stress is inherent to the adaptation process, and individuals have the capability to cope with stress factors and the potential to progress toward desired outcomes (Berry, 2006).

Berry's (2005) acculturation theory explains cultural change as a universal phenomenon observed when two distinct cultures come in direct contact. As such, acculturation is not confined to one group or geographic location. Berry further asserts that acculturation is not a uniform process; it varies according to the range of strategies adopted by individuals who are immersed in cultural change and the socio-cultural contexts of the host country. Despite many benefits, this theory does not sufficiently address the varied experiences of the international student population because it focuses mostly on immigrants' adaptation to a new culture such as life pattern change and identity development. The conceptual model presented here addresses this limitation and demonstrates the relationship between acculturation stress and mental health challenges among international students from collectivist Asian cultures adapting to the individualist American culture.

\subsection{Body of Literature}

Depression is one of the major mental health concerns for international students, and studies have indicated a positive association between acculturation stress and depression (Dao, Lee, \& Chang, 2007; Zhang \& Goodson, 2011). Asian international students who desire to attain academic success based on their cultural expectations may be particularly vulnerable to depression (Wei et al., 2007). Asian students commonly equate their self-worth with academic success and find it difficult to cope with the idea of failing. This expectation involves more than 
personal pride; it is how these particular students bring honor to their family ( $\mathrm{Li} \& \mathrm{Lin}, 2014)$. This perception of self-worth adds more stress. In addition, when confronted with challenges, Asian international students tend to rely on familial relationships for support. These students may perceive it as culturally inappropriate to speak of personal problems with people outside of their primary support group; sharing these problems with outsiders may evoke feelings of shame and guilt (Moore \& Constantine, 2005). Moreover, a greater culturally-based negative attitude toward mental illness prevents them from seeking help (Constantine, Kindaichi, Okazaki, Gainor, \& Baden, 2005).

In their study examining Korean international students living in the US, Lee et al. (2004) found that students with high levels of acculturation stress were more vulnerable to depression. Consistent with these findings, Ying and Han (2006) examined 155 Taiwanese students pursuing graduate education in 31 states and found that acculturation stress was a strong predictor of depression. Those students who experienced high levels of acculturation stress in their first semester were more likely to develop depression in their third semester. Moreover, depressive symptoms have been found to have a direct effect on suicidal ideation for Asian international students (Yang \& Clum, 1994).

Studies have identified social support as a protective factor that reduces the negative impact of acculturation stress upon the mental health of international students (Lee et al., 2004; Zhang, 2012). Many international students rely more on informal sources of support such as friends and families to mitigate negative adjustment responses during the transitional phase (Zhai, 2004). According to Nilsson, Berkel, Flores, and Lucas (2004), only $2 \%$ of international students utilized counseling services provided by their university during a given academic year. This is consistent with what Yakushko, Davison, and Sanford-Martens found (2008) during a five-year period - only $1.8 \%$ of the international student body sought help at their school's counseling center. Prior to coming to the US, the vast majority of international students had depended on family and friends in their homeland as a primary source of support to lessen their stress. However, when coming to the US, they lose the direct emotional support from family and friends and experience a sense of isolation. Such deprivation from their typical support network exacerbates alienation. This may be especially true for Asian students whose culture values close personal relationships and prioritizes family support (Heppner et al., 2006). The impact of acculturation stress on these students could be far greater than the impact on those from non-collectivist cultures.

Asian international students are often more likely to experience high levels of adjustment difficulties due to additional stressors imposed by different cultural expectations (Liao \& Wei, 2014). However, little is known about how prevalent mental health problems are among this cultural population. Therefore, it is extremely important to explore the relationship between acculturation stress and mental health, as well as potential contributing factors, in order to address this issue adequately. The next section presents an expansion of Berry's (2005) acculturation theory in order to provide a more holistic understanding of acculturation stress experienced by Asian international students. The box labeled "stressors" in Figure 1 is unique to the target students. We included this in our expansion of Berry's general acculturation model, which only diagrams a long-term adaptation process, but not short-term adjustment. Moreover, we include additional components of the acculturation process to underscore the complex nature of students' cross-cultural experiences. By highlighting the interconnected nature of the concepts, the conceptual model below provides a roadmap for examining the relationship between acculturation stress and mental health outcomes. Although the linear layout has its limitations, this conceptual map will identify a knowledge gap in the literature and highlight the need for future studies.

\section{Conceptual Model for Acculturation Stress and Mental Health Concerns}

The conceptual model of acculturation stress and mental health concerns among Asian international students is presented in Figure 1. The model contains Berry's key constructs of acculturation stress and mental health, with emphasis on stressors for Asian international students. Allowing for the general application of acculturation theory, the framework shows the process of cultural change, potential acculturation stressors, cognitive appraisals of stressful situations, the role of social support, and predicted mental health outcomes (both positive and negative). The conceptual map does not cover prior stressful events or negative experiences. 


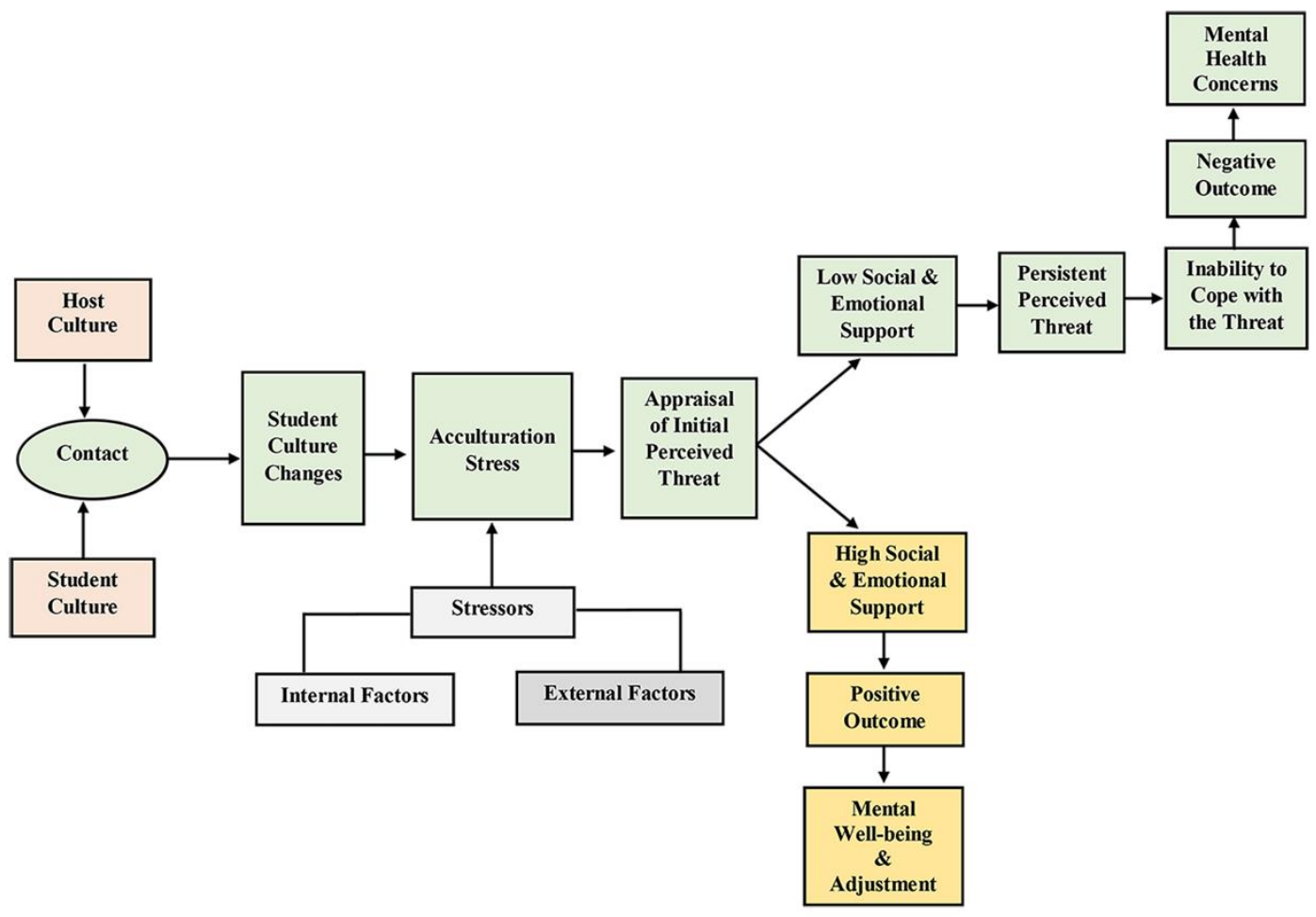

Figure 1. Diagram of a General Acculturation Framework

\subsection{Student Cultural Changes}

Direct contact between student culture and individualist American host culture yields inevitable cultural changes that demand culture learning and culture shedding. These changes are multidimensional, pervasive, and involve psychological, behavioral, and cultural aspects. Although the linear layout of this conceptual map does not adequately illustrate it, the changes are bi-directional (Berry, 1992), affecting both host and student cultures simultaneously. However, more profound cultural changes are expected to occur in the students as they are required to learn and operate within the host culture to attain their academic goals. As shown in Figure 1, it is these cultural changes that can lead to acculturation stress.

\subsection{Acculturation Stress}

While adjusting to a different culture and a new academic setting, many international students experience acculturation stress, which is manifested in Figure 1 as internal and external stressors. Although some may argue that acculturation stress is universal among international students, its severity is potentially far greater in Asian international students, because of marked differences from Western culture (Sam, 2001).

\subsubsection{Internal Stressors}

Potential internal stressors include second language anxiety (Cheng \& Erben, 2012), desire to excel academically (Liao \& Wei, 2014; Yan \& Berliner, 2011), homesickness (Liu, 2009), feelings of loneliness and/or isolation (Bertram, Poulakis, Elsasser, \& Kumar, 2014), and uncertainty of the future (Yan \& Berliner, 2011). Learning a new language and applying it to real-life situations may significantly elevate psychological discomfort. Persistent apprehension, associated with real or anticipated communication with host culture members, may result in emotional and psychological distress among Asian international students. Related to language anxiety, fear of inadequate performance in evaluative situations will likely increase negative emotions, while desire to succeed academically may add additional pressure. In general, collectivist cultures are characterized by close relationships with the small in-group (Triandis, 1975). Relocating to a new culture, the students may often experience homesickness, grieving for the loss of support networks. This disrupted social connection would potentially exacerbate feelings of loneliness and/or isolation. The tension between collectivist and individualist cultures can yield superficial relationships with host nationals which do not compensate for the loss of this support network. Lastly, uncertainty over the future looms large over international students during their studies in the host country (Yan \& Berliner, 2011); visa status, potential deportations, changing political climate, and 
genuine uncertainty regarding the successful completion of study all feed acculturation stress.

\subsubsection{External Stressors}

Potential external stressors are the language barrier (Dao et al., 2007), interpersonal problems (Liu, 2009), academic challenges (Zhai, 2004), financial constraints (Kwon, 2009), and unfair treatment/discrimination (Poyrazli \& Lopez, 2007). Language barriers may impede meaningful relationships with American peers and faculty members. They affect academic performance as well. Interpersonal problems may cause overwhelming feelings of loneliness, isolation, and hopelessness. Specific to the classroom culture, Asian students oftentimes learn through a traditional method in which the teacher lectures and students assume a passive role in their learning. This method stands in contrast to some Western pedagogical methods emphasizing interactive learning; therefore, adjusting to different teaching methods and classroom dynamics may cause psychological difficulties (Smith \& Khawaja, 2011; Zhai, 2004). Financial pressure is enormous for many international students because in general, they are not allowed to work outside the university (Lee et al., 2004). On-campus jobs are usually limited, and international students are not eligible for American federal loans. Financial constraints may force them to accelerate their study to a shorter period of time in order to expedite graduation and ease the financial burden on their family. This added stress could increase the likelihood of developing mental health problems, such as anxiety, feelings of inadequacy, and depression. Lastly, categorized as a minority group, the students are sometimes subject to unfair treatment, which may significantly reduce their psychological well-being. However, as Sandhu (1994) notes, drawing a sharp distinction between internal and external stressors may be a difficult task due to a linkage between the two, as well as the lack of research on the topic.

\subsection{Appraisal, Social Support, and Mental Health Outcomes}

When confronted with acculturation challenges, Figure 1 illustrates that individual students cognitively appraise their situations in two steps: first assessing whether the presented challenge is a threat and then seeking resources to cope with it (Lazarus \& Folkman, 1984). Social support is effective when acculturation stress is high (Zhang, 2012). In fact, students with strong social support networks are less likely to assess their acculturation experiences as stressful events (Yeh \& Inose, 2003), which makes successful adjustment to the new culture more likely. As seen in Figure 1, this would result in mental well-being. Such support can buffer the negative effects of acculturation stress. Conversely, students with a low level of social support are more likely to perceive their acculturation experiences as a threat to their mental well-being. These particular students undergo the appraisal process repeatedly, and with insufficient social support, they are often faced with excessive stress that could overwhelm their coping ability. If this stress is not resolved, it is perceived as a persistent threat to their mental well-being. Recurring struggles with this persistent perceived threat are debilitating and may lead to negative mental health outcomes.

Repeated exposure to stress may interfere with normal functioning of international students by increasing their psychological vulnerabilities (Smith \& Khawaja, 2011; Wei et al., 2007). One possible manifestation of this process is students' internalization of their vulnerabilities and changes in their perception of themselves and the outside world. Research has documented a link between acculturation stress and mental health conditions for international students, manifested by anxiety, depression, and suicidal ideation (Liu, 2009; Yang \& Clum, 1994; Zhang \& Goodson, 2011). While there is a lack of research on international students' suicide statistics, connections still can be made between severe prolonged acculturation stress and suicidal behavior. Given the magnitude of these problems, it is important to understand the intricate connection between acculturation stress and mental health challenges in order to assist the international student population effectively during their transitional phase.

\section{Discussion}

The purpose of this paper is to present a conceptual model that expands Berry's acculturation theory by exploring the relationship between acculturation stress and mental health concerns among Asian international students. This conceptual model, in expanding Berry's theory, addresses stressors identified specifically in these students. It explains social factors affecting the mental well-being of Asian international students and enables colleges to meet the psychological needs of this group.

When their home culture comes into direct contact with the host culture, many Asian international students experience changes caused by conflicting norms and values, different expectations, and unfamiliar educational systems. With limited adaptive resources, cultural and environmental demands turn into acculturation stress. The conceptual model indicates the link between acculturation stress and mental health, and explores students' coping strategies with greater attention on the role that social support plays in mitigating the negative impact of acculturation stress. This highlights the necessity for higher learning institutes to develop services and programs best suited to the needs of this student population. 
The strength of this modified model is that it illustrates a complex acculturation process that can be applied to different culture groups. The model also delineates the connection between acculturation stress and mental health outcomes. A general acculturation framework developed from immigrants' experiences is based on the three linear steps of stress-coping-adaptation (Berry, 2005). This general framework suggests that psychological strains that arise during initial intercultural encounters decrease with time. This approach reinforces cultural adaptation as a long-term goal, while providing a limited explanation of the impact of acculturation stress on mental health for Asian international students who, because of their educational goals, stay in the host culture for a limited time. Largely, their acculturation focuses on acting strategically in order to succeed academically. Employing an ecological perspective, the revised conceptual model presented in this paper fills in the knowledge gap existing in the literature by providing a holistic understanding of acculturation stress experienced by Asian international students living in an individualist culture. Another strength of this conceptual model is that, despite the inherent challenges of isolating internal acculturation stressors from external ones, it provides a roadmap for examining both stressors and offers a more comprehensive understanding of the acculturation process among Asian international students.

A limitation of this conceptual model is that it is unidirectional. The conceptual model shows changes only in students' cultures, whereas the host culture appears to remain the same. Though acculturation stress is experienced only by those entering into the host culture, as Berry (1991) points out, when two cultures come in direct contact, changes are expected to be mutual. Even though it might seem like a limitation, the unidirectional model feels necessary in this context precisely because international students will not be in the host country long enough for the host country to feel the need to adapt to their presence. Another limitation is that the conceptual model does not clearly explicate idiosyncrasies existing within the student group and assumes that individuals experience the same or similar acculturation processes regardless of their backgrounds, including the influence of previous stressful events. Furthermore, the conceptual model emphasizes conformity to the preexisting reality of the host culture, allowing little or no room for either structural changes or an examination of the power dynamics between Asian international students and members of the host culture. Finally, the model addresses individuals with the potential to change and adapt to the new environment, but does not see them as co-constructors of their environment or reality. As a result, Asian international students are subject to the dominant culture of the university. This could inadvertently perpetuate institutional inequality. Despite these limitations, this revised conceptual model is necessary to explain the particulars of acculturation stress experienced by Asian international students.

\section{Conclusion}

This exploration highlights the need for empirical studies related to acculturation stress among international students. Because there are many ambiguities, what is actually transpiring in the classroom has yet to be analyzed. The revised model provides details and contexts to understand the acculturation process of Asian international students. Such a model furthers Berry's acculturation framework and addresses short-term mental health issues largely overlooked in this group. However, the model does not look into classroom dynamics, university setting, faculty demographics, and student interactions with the outside community. For example, faculty understanding of student culture and support from US-born peers are assumed to decrease acculturation stress. Studies evaluating the impact of diversity programs on the cultural awareness of host-culture students would aid intercultural understanding. Most available literature examining the link between acculturation stress and the mental health of international students uses quantitative methods, treating acculturation as a single experience occurring in an expected timeframe. Qualitative research using in-depth interviews will detail the acculturation experiences of students during their time in the US and more accurately represent the multifaceted nature of the acculturation process.

Although this manuscript is confined to international students from Asian collectivist cultures, it may be applied to other international students who study in the US. The conceptual model emphasizes the importance of on-going social support and the need for universities to further develop services and programs that support international students. For example, universities may provide education for faculty and staff regarding the acculturation experience. Orientations for new international students tend to focus on academic-related information, but this time could also be used to promote support services for those who are unfamiliar with the new system and cultural expectations. Promotion of campus resources can be beneficial in addressing both internal and external stressors that international students experience during their transition period.

For clinical implications, creating a consultation group of various ethnic groups could help meet the unique needs of international students. It is imperative to recognize the unique struggles of international students and address them in a culturally sensitive manner. The conceptual model in this manuscript may be used as a 
template for academic institutes in the US to understand the acculturation experience. Detailed descriptions of stressors and coping strategies in this revised model will help universities to intervene and support international students in a timely and proactive manner. By further investigating acculturation challenges, this manuscript may provide a better context of student interactions with their academic environment and how these interactions impact the adjustment of this population.

\section{Acknowledgements}

I would like to express my heartfelt gratitude to my writing team-Anne Wenger, Greg Arcaro, Jason Brody, and Martin Davy - for their insightful comments and suggestions throughout the entire creation of this manuscript.

\section{References}

Berry, J. W. (1991). Understanding and managing multiculturalism: Some possible implications for research in Canada. Psychology and Developing Societies, 3, 17-49. https://doi.org/10.1177/097133369100300103

Berry, J. W. (1992). Acculturation and adaptation in a new society. International Migration, 39, 69-85. https://doi.org/10.1111/j.1468-2435.1992.tb00776.x

Berry, J. W. (1997). Immigration, acculturation, and adaptation. Applied Psychology: An International Review, $46(1), 5-68$.

Berry, J. W. (2005). Acculturation: Living successfully in two cultures. International Journal of Intercultural Relations, 29, 697-712. https://doi.org/10.1016/j.ijintrel.2005.07.013

Berry, J. W. (2006). Stress perspectives on acculturation. In D. L. Sam \& J. W. Berry (Eds.), The Cambridge handbook of acculturation psychology (pp. 43-57). New York, NY: Cambridge University Press.

Berry, J. W., Kim, U., Minde, T., \& Mok, D. (1987). Comparative study of acculturative stress. International Migration Review, 21(3), 491-511. https://doi.org/10.1177/019791838702100303

Bertram, D. M., Poulakis, M., Elsasser, B. S., \& Kumar, E. (2014). Social support and acculturation in Chinese international students. Journal of Multicultural Counseling and Development, 42(2), 107-124. https://doi.org/10.1002/j.2161-1912.2014.00048.x

Cheng, R., \& Erben, A. (2012). Language anxiety: Experiences of Chinese graduate students at U.S. higher institutions. Journal of Studies in International Education, 16(5), 477-497. https://doi.org/10.1177/1028315311421841

Constantine, M. G., Kindaichi, M., Okazaki, S., Gainor, K. A., \& Baden, A. (2005). A qualitative investigation of the cultural adjustment experiences of Asian international college women. Cultural Diversity and Ethnic Minority Psychology, 11(2), 162-175. https://doi.org/10.1037/1099-9809.11.2.162

Coon, H. M., \& Kemmelmeier, M. (2001). Cultural orientations in the United States: (Re)examining differences among ethnic groups. Journal of Cross-Cultural Psychology, 32(3), 348-364. https://doi.org/10.1177/0022022101032003006

Dao, T. K., Lee, D., \& Chang, H. L. (2007). Acculturation level, perceived English proficiency, perceived social support level, and depression among Taiwanese international students. College Student Journal, 41, 287-295.

Gudykunst, W. B. (2005). An anxiety/uncertainty management (AUM) theory of strangers' intercultural adjustment. In W. B. Gudykunst (Ed.), Theorizing about intercultural communication (pp. 419-457). Thousand Oaks, CA: Sage.

Hays, D., \& Erford, B. (2014). Developing multicultural counseling competence: A systems approach. Upper Saddle River, NJ: Pearson.

Heppner, P. P., Heppner, M. J., Lee, D-G., Wang, Y-W., Park, H-J., \& Wang, L. (2006). Development and validation of a collectivist coping styles inventory. Journal of Counseling Psychology, 53(1), 107-125. https://doi.org/10.1037/0022-0167.53.1.107

Hui, C. H., \& Triandis, H. C. (1986). Individualism-collectivism: A study of cross-cultural researchers. Journal of Cross-Cultural Psychology, 17(2), 225-248. https://doi.org/10.1177/0022002186017002006

Institute of International Education. (2019). Open doors 2019. Retrieved from https://p.widencdn.net/6tpaeo/Open-Doors-Annual-Data-Release-2019-11-17-Print

Kim, B. S., Li, L. C., \& Ng, G. F. (2005). The Asian American value scales-multidimensional: Development, reliability, and validity. Cultural Diversity and Ethnic Minority Psychology, 11, 187-201. 
https://doi.org/10.1037/1099-9809.11.3.187

Kuo, B. C. (2014). Coping, acculturation, psychological adaptation among migrants: A theoretical and empirical review and synthesis of literature. Health Psychology and Behavioral Medicine, 2(1), 16-33. https://doi.org/10.1080/21642850.2013.843459

Kwon, Y. (2009). Factors affecting international students' transition to higher education institutions in the United Sates: From the perspective of Office of International Students. College Student Journal, 43(4), 1020-1036.

Lazarus, R., \& Folkman, S. (1984). Stress, appraisal, and coping. New York, NY: Springer Publishing Company.

Lee, J. S., Koeske, G. F., \& Sales, E. (2004). Social support buffering of acculturative stress: A study of mental health symptoms among Korean international students. International Journal of Intercultural Relations, 28, 399-414. https://doi.org/10.1016/j.ijintrel.2004.08.005

Li, C-S., \& Lin, Y-F. (2014). Understanding Asian international college students' values and beliefs, their academic stress and coping strategies. Journal of Education and Human Development, 3(4), 59-64. http://dx.doi.org/10.15640/jehd.v3n4a5

Liao, K. Y-H., \& Wei, M. (2014). Academic stress and positive affect: Asian value and self-worth contingency as moderators among Chinese international students. Cultural Diversity and Ethnic Minority Psychology, 20(1), 107-115. https://doi.org/10.1037/a0034071

Liu, M. (2009). Addressing the mental health problems of Chinese international college students in the United States. Advances in Social Work, 10(1), 69-86. https://doi.org/10.18060/164

Moore, J. L., III, \& Constantine, M. G. (2005). Development and initial validation of the collectivistic coping styles measures with African, Asian, and Latin American international students. Journal of Mental Health Counseling, 27(4), 329-347. https://doi.org/10.17744/mehc.27.4.frcqxuy1we5nwpqe

Nilsson, J. E., Berkel, L. A., Flores, L. Y., \& Lucas, M. S. (2004). Utilization rate and presenting concerns of international students at a university counseling center: Implications for outreach programming. Journal of College Student Psychotherapy, 19, 49-59. https://doi.org/10.1300/J035v19n02_05

Poyrazli, S., \& Lopez, M. D. (2007). An exploratory study of perceived discrimination and homesickness: A comparison of international students and American students. The Journal of Psychology, 141(3), 263-280. https://doi.org/10.3200/JRLP.141.3.263-28

Sam, D. L. (2001). Satisfaction with life among international students: An exploratory study. Social Indicators Research, 53, 315-337. https://doi.org/10.1023/A:1007108614571

Sandhu, D. S. (1994). Examination of psychological needs of the international students: Implication for counseling and psychotherapy. International Journal for the Advancement of Counselling, 17, 229-439.

Schwartz, S. J., Unger, J. B., Zamboanga, B. L., \& Szapocznik, J. (2010). Rethinking the concept of acculturation: Implications for theory and research. American Psychologist, 65(4), 237-251. https://doi.org/10.1037/a0019330

Smart, J. F., \& Smart, D. W. (1995). Acculturative stress: The experience of the Hispanic immigrant. The Counseling Psychologist, 23(1), 25-42. https://doi.org/10.1177/0011000095231003

Smith, R. A., \& Khawaja, N. G. (2011). A review of the acculturation experiences of international students. International Journal of Intercultural Relations, 35, 699-713. https://doi.org/10.1016/j.ijintrel.2011.08.004

Triandis, H. C. (1995). Individualism \& collectivism. Boulder, CO: Westview Press.

UNESCO Institute for Statistics. (2006). Global digest education 2006. Quebec, Canada: UNESCO Institute for Statistics.

Voronov, M., \& Singer, J. A. (2002). The myth of individualism-collectivism: A critical review. The Journal of Social Psychology, 142(4), 461-480. https://doi.org/10.1080/00224540209603912

Wei, M., Heppner, P. P., Mallen, M. J., Ku, T., Liao, K. Y., \& Wu, T. (2007). Acculturative stress, perfectionism, years in the United States, and depression among Chinese international students. Journal of Counseling Psychology, 54(4), 385-394. https://doi.org/10.1037/0022-0167.54.4.385

Yakushko, O., Davidson, M. M., \& Sanford-Martens, T. C. (2008). Seeking help in a foreign land: International students' use patterns for a U.S. university counseling center. Journal of College Counseling, 11, 6-18. https://doi.org/10.1002/j.2161-1882.2008.tb00020.x 
Yan, K., \& Berliner, D. C. (2011). Chinese international students in the United States: Demographic trends, motivations, acculturation features and adjustment challenges. Asia Pacific Education Review, 12(2), 173-184. https://doi.org/10.1007/s12564-010-9117-x

Yang, B., \& Clum, G. A. (1994). Life stress, social support, and problem-solving skills predicative of depressive symptoms, hopelessness, and suicidal ideation in an Asian student population: A test of a model. Suicide and Life-Threatening Behavior, 24(2), 127-139. https://doi.org/10.1111/j.1943-278X.1994.tb00797.x

Yeh, C. J., \& Inose, M. (2003). International students' reported English fluency, social support satisfaction, and social connectedness as predictors of acculturative stress. Counselling Psychology Quarterly, 16, 15-28. https://doi.org/10.1080/0951507031000114058

Ying, Y., \& Han, M. (2006). The contribution of personality, acculturative stressors, and social affiliation to adjustment: A longitudinal study of Taiwanese students in the United States. International Journal of Intercultural Relations, 30(5), 623-635. https://doi.org/10.1016/j.ijintrel.2006.02.001

Zea, M. C., Asner-Self, K. K., Birman, D., \& Buki, L. P. (2003). The abbreviated multidimensional acculturation scale: Empirical validation with two Latino/Latina samples. Cultural Diversity and Ethnic Minority Psychology, 9(2), 107-126. https://doi.org/10.1037/1099-9809.9.2.107

Zhai, L. (2004). Studying international students: Adjustment issues and social support. Journal of International Agricultural and Extension Education, 11(1), 97-104. https://doi.org/10.5191/jiaee.2004.11111

Zhang. J., \& Goodson, P. (2011). Predictors of international students' psychosocial adjustment to life in the United States: A systematic review. International Journal of Intercultural Relations, 35, 139-162. https://doi.org/10.1016/j.ijintrel.2010.11.011

Zhang, Y. (2012). An examination of acculturative stress, perceived social support, and depression among Chinese international students (Master's thesis, Syracuse University, New York, USA). Retrieved from http://surface.syr.edu/cgi/viewcontent.cgi?article=1002\&context=cfs_thesis

\section{Copyrights}

Copyright for this article is retained by the author(s), with first publication rights granted to the journal.

This is an open-access article distributed under the terms and conditions of the Creative Commons Attribution license (http://creativecommons.org/licenses/by/4.0/). 